\title{
Catalytic asymmetric synthesis using chirality-switchable helical polymer as a chiral ligand
}

\section{$\operatorname{AUTHOR}(\mathrm{S}):$}

Suginome, Michinori; Yamamoto, Takeshi; Nagata, Yuuya; Yamada, Tetsuya; Akai, Yuto

\section{CITATION:}

Suginome, Michinori ... [et al]. Catalytic asymmetric synthesis using chirality-switchable helical polymer as a chiral ligand. Pure and Applied Chemistry 2012, 84(8): 1759-1769

\section{ISSUE DATE:}

2012-02

URL:

http://hdl.handle.net/2433/194096

RIGHT:

(C) 2012 IUPAC 
Pure Appl. Chem., Vol. 84, No. 8, pp. 1759-1769, 2012.

http://dx.doi.org/10.1351/PAC-CON-11-08-23

(C) 2012 IUPAC, Publication date (Web): 3 February 2012

\title{
Catalytic asymmetric synthesis using chirality-switchable helical polymer as a chiral ligand*
}

\author{
Michinori Suginome ${ }^{1,2, \ddagger}$, Takeshi Yamamoto ${ }^{1}$, Yuuya Nagata ${ }^{1}$, \\ Tetsuya Yamada ${ }^{1}$, and Yuto Akai ${ }^{1}$ \\ ${ }^{1}$ Department of Synthetic Chemistry and Biological Chemistry, Kyoto University, \\ Kyoto, Japan; ${ }^{2}$ CREST, JST, Katsura, Nishikyo-ku, Kyoto 615-8510, Japan
}

\begin{abstract}
Single-handed PQXphos, i.e., helical poly(quinoxaline-2,3-diyl)s bearing diarylphosphino pendant groups, served as remarkable chiral ligands in palladium-catalyzed asymmetric hydrosilylation of styrenes and asymmetric biaryl synthesis by Suzuki-Miyaura coupling, affording up to $98 \%$ enantiomeric excess (e.e.) in both reactions. A palladium complex of high-molecular-weight variant (1000mer) of PQXphos could be reused eight times by virtue of the formation of an insoluble polymer complex. PQXphos underwent solvent-dependent inversion of the helical sense, enabling production of either of two enantiomeric products using a single PQXphos.
\end{abstract}

Keywords: asymmetric catalysis; cross-coupling reactions; helical polymer; helix inversion; hydrosilylation; macromolecular chemistry; organometallic chemistry; palladium catalysis; phosphine ligand; polymerization; switch of chirality.

\section{INTRODUCTION}

Much interest has focused on polymer-based chiral ligands in catalytic asymmetric synthesis [1]. They have advantages over the conventional low-molecular-weight chiral ligands in that they are easily separable from the reaction mixtures and reusable by virtue of their heterogeneity in certain solvents. It seems likely that they will find more applications in organic synthesis, especially in industrial production, taking advantage of those favorable aspects of the polymer-based catalysts. The molecular designs of the existing polymer-based chiral ligands, however, do not appear to be based on the unique structural and conformational properties of macromolecules. The macromolecular scaffolds are rather utilized just to immobilize the catalytically active chiral units into their side chains or main chains. In this conventional molecular design, efforts are made to avoid a strong steric influence of the polymer scaffold on the chiral reaction environments created by the immobilized small chiral groups.

In contrast, there exists a different molecular design in which chiral polymer scaffolds play a key role in enantiodiscrimination. This type of molecular design seems to be highly attractive and unique, because of some desirable features of the polymer scaffolds such as their enormously large steric hindrance, stimuli-responsive conformational changes, and the possibility of designed spatial arrangement of multiple functionalities. However, polymer-based chiral catalysts classified in this category are quite rare. Obviously, the conformational flexibility and structural ambiguity of the macromolecular scaffolds

*Pure Appl. Chem. 84, 1673-1784 (2012). A collection of invited papers based on presentations at the $16^{\text {th }}$ International Symposium on Organometallic Chemistry Directed Towards Organic Synthesis (OMCOS-16), Shanghai, China, 24-28 July 2011.

¥Corresponding author 
have hampered design and synthesis of such new-generation chiral polymer catalysts. Exploration of such polymer scaffolds that enable direct enantiodiscrimination would be very attractive and challenging not only for organic synthesis, but also for polymer sciences.

Such challenges started with the use of macromolecular scaffolds found in nature. Polypeptide and DNA were utilized as scaffolds for chiral catalysts by incorporation of catalytically active sites covalently or noncovalently [2,3]. Taking advantage of the highly ordered 3D structure of DNA, highly effective enantiodiscrimination has been achieved with DNA-based catalysts, in which a ligand moiety for coordination to copper was introduced to the DNA backbone by intercalation [3]. It showed remarkably high enantioselectivity up to $99 \%$ enantiomeric excess (e.e.) in the asymmetric Diels-Alder reaction. As is clearly shown by the example, macromolecular scaffolds are able to serve as a key element of enantiodiscrimination. It should be noted, however, that nature produces just one of the two enantiomeric forms in general, thus making application to practical asymmetric synthesis difficult.

Use of fully synthetic macromolecules can allow us to avoid the problem of low availability of enantiomeric catalysts. Use of chiral helical polymers could be promising because many nonracemic helical polymers are known and, in ideal cases, the structural homogeneity of the helical backbone is secure [4]. A pioneering work by Regellin et al. appeared in 2002 [5]. They took Okamoto's helical poly(trityl methacrylate) scaffolds [6] in their polymer catalyst with modification of the triphenylmethyl group with the bis(2-pyridyl)phenylmethyl group for coordination to palladium. The polymer ligand for the first time showed enantiodiscrimination by the chiral synthetic polymer. However, this example did not successfully ensure the fruitful future of synthetic helical polymers as chiral catalysts, because the enantioselectivity obtained in the palladium-catalyzed asymmetric allylation was still moderate $(60 \%$ e.e.), and high catalyst loading ( $25 \mathrm{~mol} \%$ ) was required. It seems to be essential to find new helical polymer scaffolds to overcome the difficulty and to open up new possibilities of chiral polymer catalysts.

We were particularly interested in using the scaffold of poly(quinoxaline-2,3-diyl)s (PQXs hereafter) as the key element of enantiodiscrimination. Some unique features of PQXs were reported by Ito's research group [7]. They are synthesized by living aromatizing polymerization of 1,2-diisocyanobenzenes, which allows easy control of polymerization degrees and molecular weight dispersity by virtue of the living nature of the reaction. They are assumed to have helical structures and, more interestingly, the possibility of the existence of nonracemic helical structures has been shown [8]. Our contribution to the chemistry of PQX started with the exploration of easy synthetic access to singlehanded PQXs. We have developed two different approaches to single-handed PQXs. One strategy is to use a chiral organopalladium complex as an initiator for the polymerization, allowing us to obtain as high as $84 \%$ screw-sense excess (s.e.) for 40mer PQX [9]. A more recent and reliable strategy is to use monomer bearing chiral side chains [10]. This strategy allows almost perfect control of the screw-sense of PQXs. We utilized these single-handed PQXs as a scaffold for chiral polymer ligands.

In this article, we describe our recent attempts at using the PQX-based monodentate phosphine ligand in palladium-catalyzed hydrosilylation of styrenes and asymmetric Suzuki-Miyaura coupling giving axially chiral biaryls [11-13]. We initially used macromolecules having relatively low molecular weight to check the structure/selectivity relationship carefully, and then employed high-molecularweight macromolecules including 1000mer. These examinations provided some key features of the PQX-based ligand through enantioselectivities higher than the corresponding low-molecular-weight chiral ligands, high reusability of the catalysts, and production of both enantiomers from the single catalyst by utilizing the solvent-dependent switch of helical chirality of PQX scaffolds. 


\section{MOLECULAR DESIGN OF POLY(QUINOXALINE-2,3-DIYL)-BASED CHIRAL LIGANDS, PQXphos}

With the unique single-handed helical polymer scaffolds in hand, the molecular design for introduction of coordinating groups onto the scaffolds is critically important. We initially chose monophosphine coordinating groups, primarily because of the lack of variation of chiral monodentate ligands in comparison with the enormous variation of bidentate ligands. Furthermore, monodentate phosphines seem to be more suitable for introduction to the polymer scaffold, given that phosphine oxides formed inevitably by oxidation cannot be wiped away from the polymer catalyst. Use of a diphosphine coordinating group in the polymer catalyst may leave a small portion of phosphine-phosphine oxide moiety, which would have higher reactivity than the desirable diphosphine moiety and thus lower the enantioselectivity. We expected that a monophosphine coordinating group would just be oxidized to catalytically inactive phosphine oxide.

Our molecular design involves introduction of a 2-diarylphosphinophenyl group directly to the 5-position of the quinoxaline ring (Fig. 1). The quinoxaline-phenyl axis is intrinsically free rotating, unless the effect of the chiral polymer scaffold is taken into account. In reality, however, the helical scaffolds would make favorable one of the two axial chiralities at the quinoxaline-phenyl bond. We expected that the "induced axial chirality" would help the polymer ligand serve as a highly efficient chiral ligand in catalytic asymmetric synthesis.

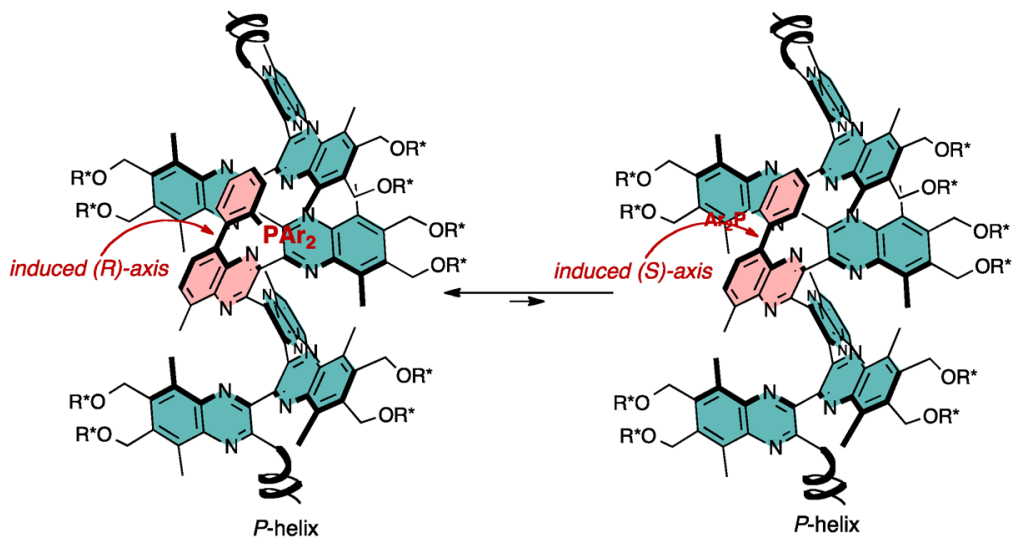

Fig. 1

The new polyquinoxaline-based chiral ligands used in this article are shown in Fig. 2. They are all prepared by polymerization of functionalized 1,2-diisocyanobenzenes using organopalladium or organonickel initiators [14]. There are basically three types of monomer units incorporated into the polymer scaffolds. One is a quinoxaline unit bearing coordinating diarylphosphino groups. Some different diorganophosphino groups were introduced into the monomer unit. The other two are achiral and chiral noncoordinating units, which bear propyloxymethyl groups and $(R)$-1-methylpropyloxymethyl groups, respectively, at the 6- and 7-positions of the quinoxaline rings. The ligands are prepared by block or random copolymerizations.

Ligand $\mathbf{L 1}$ was prepared by block copolymerization of the achiral unit and the coordinating unit. A single coordinating unit was sandwiched by the blocks of 10 (averaged) achiral units. Nonracemic right-handed $(P)$-helical sense was induced by the terminal chiral group $\left({ }^{S S} \mathrm{Ar} *\right)$, which comes originally from the chiral organopalladium initiator. L2-L7 differ from $\mathbf{L 1}$ in the number of units at the achiral and coordinating blocks. Ligand $\mathbf{L 8}$ is a heptablock copolymer that was prepared by repetitive addition of two monomers. Ligands L9-L12 are also 20mer-based chiral ligands, but now contain chiral 


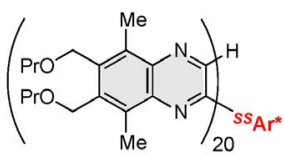

LO

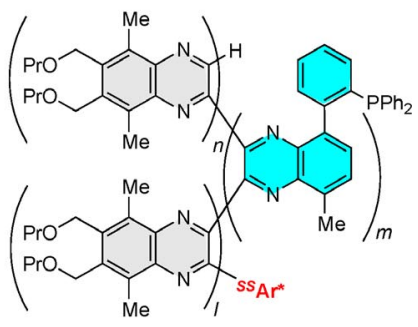

$\mathbf{L} 1(i, m, n=10,1,10)$ L2 $(i, m, n=30,1,10)$ L3 $(i, m, n=10,1,30)$ L4 $(i, m, n=10,1,0)$ L5 $(i, m, n=10,2,10)$ 6 $6(i, m, n=10,3,10)$ L7 $(i, m, n=10,5,10)$

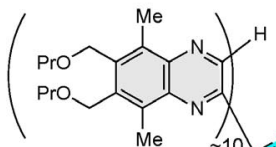

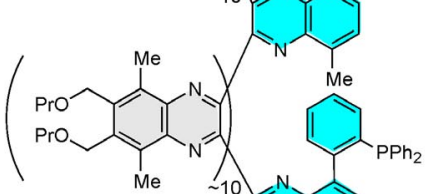

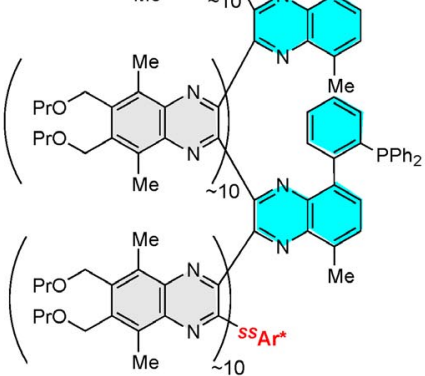

L8

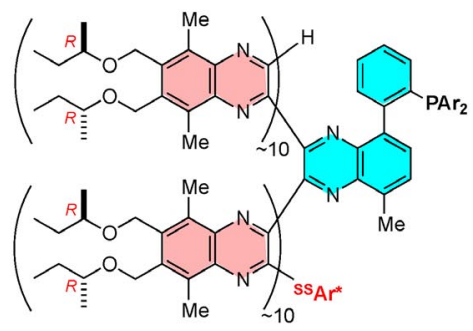

$\mathrm{L9}(\mathrm{Ar}=\mathrm{Ph})$

$\mathrm{L} 10(\mathrm{Ar}=3,5-\mathrm{Xy})$

L11 $(\mathrm{Ar}=p-\mathrm{Tol})$

$\mathrm{L} 12\left(\mathrm{Ar}=3,5-\left(\mathrm{CF}_{3}\right)_{2} \mathrm{C}_{6} \mathrm{H}_{3}\right)$

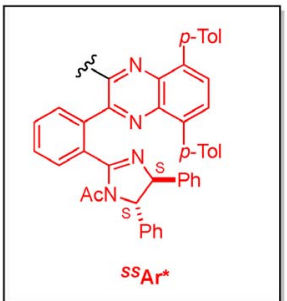

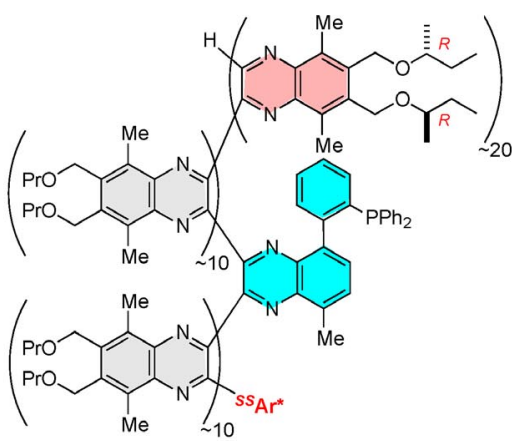

L13

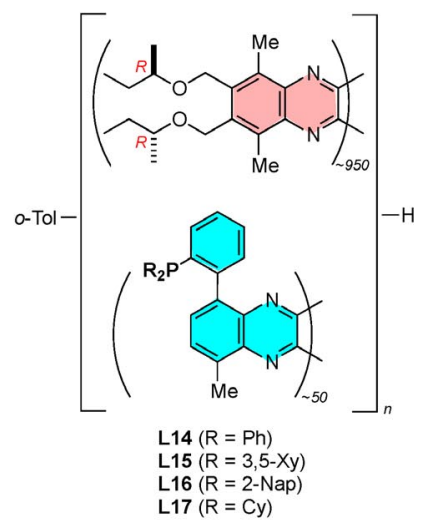

Fig. 2

noncoordinating units instead of the achiral unit to improve the screw-sense purity. L13 was prepared for checking the effect of the chiral side chain on the creation of a chiral reaction environment by keeping the reaction site apart from the chiral group. Ligands L14-L17 are 1000mer-based, high-molecular-weight polymers in which chiral noncoordinating units are used in addition to the four different coordinating groups. In these high-molecular-weight PQXphos, no chiral terminal group is used. They were synthesized by random copolymerization using an achiral organonickel initiator.

\section{ASYMMETRIC HYDROSILYLATION OF STYRENES USING POLYQUINOXALINE-BASED CHIRAL MONODENTATE PHOSPHINE (PQXphos)}

We chose palladium-catalyzed hydrosilylation of styrenes as the model reaction, because chiral monodentate phosphine ligands were reported to give high enantioselectivities. Alternative use of bidentate phosphine ligands always suffers from poor reactivity as well as low enantioselectivities. The 
MOP-type ligands developed by Hayashi and Uozumi achieved remarkably high enantioselectivities in this reaction [15].

All of the polymer ligands PQXphos L1-L17 were soluble in common organic solvents such as toluene, tetrahydrofuran (THF), dichloromethane, and chloroform. The catalyst was prepared by mixing solutions of $\mathrm{PQXphos} \mathrm{in} \mathrm{toluene} \mathrm{and}[\mathrm{PdCl}(\pi \text {-allyl })]_{2}$ in toluene at room temperature. After evaporation of toluene under reduced pressure, styrene and then trichlorosilane were introduced at $0{ }^{\circ} \mathrm{C}$ to the catalyst. The hydrosilylation product was isolated by bulb-to-bulb distillation, and a portion of the isolated product was oxidized under the Tamao conditions, which led to 1-phenylethanol for determination of the enantiomeric excess by high-performance liquid chromatography (HPLC) (Daicel OD-H).

It should be noted that PQXphos remarkably accelerates the hydrosilylation reaction, while LO, which is the homopolymer of noncoordinating units lacking a phosphorus group, showed no catalytic activity at all (Table 1). This clearly indicates that the phosphorous group of PQXphos is successfully coordinating to palladium. PQXphos L1 showed remarkable enantioselectivity of $85 \%$ e.e. in the hydrosilylation reaction (entry 1). The relationship between the polymer structure and selectivity was then checked using L2-L7 under the same reaction conditions as L1. L2 and L3, in which one of the two blocks of noncoordinating, achiral units is extended, showed essentially the same enantioselectivities as $\mathbf{L 1}$ (entries 2 and 3). The result for $\mathbf{L 2}$, in which the chiral terminal group and the coordinating group are more distant than in $\mathbf{L 1}$, clearly suggests that the enantiodiscrimination is made on the basis of the induced helical conformation. It is interesting to see that $\mathbf{L 4}$, in which the coordinating group is located at the terminus of the polymer, afforded low e.e. (entry 4). The terminal of the polymer chain may be too flexible to induce sufficient axial chirality at the quinoxaline-phenyl bond. The results with L5-L7, in which the numbers of successive coordinating groups are different, indicated that better enantioselectivity would be obtained if the coordination units are dispersed as much as possible along the polymer chain (entries 5-7). With this in mind, heptablock copolymer $\mathbf{L 8}$ was prepared and utilized in hydrosilylation, affording high e.e. (entry 8). This heptablock PQXphos takes advantage of scattered coordination units and multiple coordination sites in one molecule. The latter feature can reduce the usage of the costly organopalladium initiator per phosphorus atom.

Table 1 Palladium-catalyzed asymmetric hydrosilylation of styrene in the presence of PQXphos as chiral ligands. ${ }^{a}$

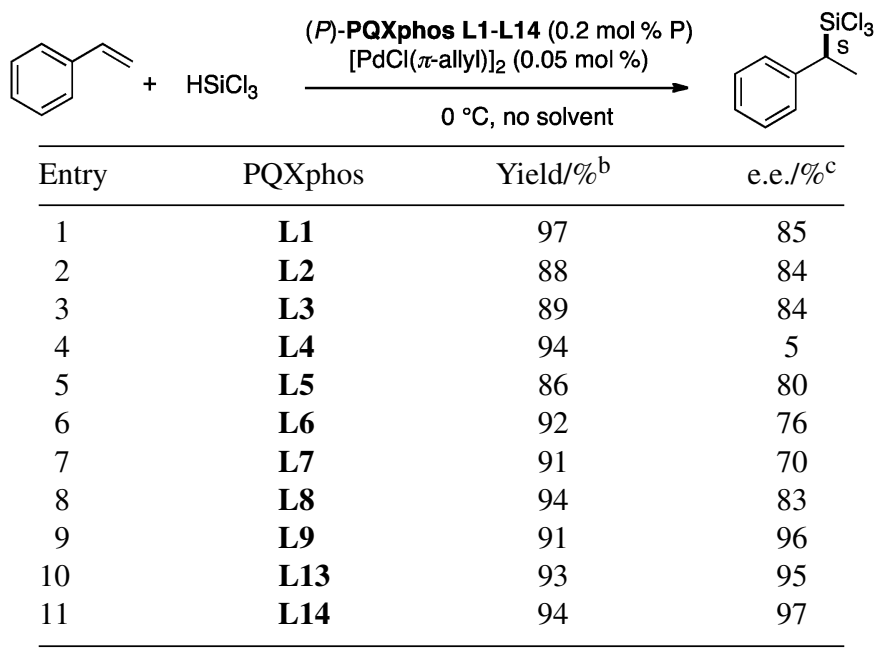

${ }^{\mathrm{a} A}$ styrene derivative and trichlorosilane (2 equiv) were stirred at $0{ }^{\circ} \mathrm{C}$ in the presence of $[\mathrm{PdCl}(\pi \text {-allyl })]_{2}(0.05 \mathrm{~mol} \%)$ with a polymer ligand $(0.2 \mathrm{~mol} \% \mathrm{P})$.

bIsolated yield.

cDetermined after oxidation to 1-phenylethanol. 
We then introduced chiral noncoordinating units instead of the achiral units. $\mathbf{L 9}$ afforded remarkably high enantioselectivity under the same reaction conditions as L1 (entry 9). The increase in e.e. can be attributed to the improved helical sense purity as a result of the chiral side chains. The high enantioselectivity observed with L13, in which the coordinating group and the chiral side chains were separated by 10 achiral units, clearly suggests that the chiral side chains have no direct effect on the creation of the chiral reaction environment, but induce the highly pure right-handed helical structure to the polymer main chain (entry 10). Finally, we found that the high-molecular-weight PQXphos L14 exhibited the best performance (97\% e.e.) among the family of PQXphos tested thus far (entry 11).

When $\mathbf{L 1 4}$ and $[\mathrm{PdCl}(\pi \text {-allyl })]_{2}$ were mixed in toluene, but the palladium complex was still soluble in toluene. After removal of the solvent followed by introduction of styrene and trichlorosilane, the mixture gradually turned turbid and finally gelled. On adding acetonitrile to the gelled reaction mixture, the hydrosilylation product could be extracted from the mixture, leaving a filmy insoluble polymer complex in the reaction vessel. The polymer complex was found to be reusable. The results of hydrosilylation with the reused catalyst are shown in Table 2. Note that no additional palladium complex was added during the reuse of the catalyst. During the eight-time reuse, no decrease in the enantioselectivity was observed. We instead observed a significant decrease in the reaction rate every time. We found there was significant leaching of the palladium metal into the acetonitrile extract, leading to the loss of catalytic activity. It is interesting to note, however, that the lost palladium metal could be recharged by adding a toluene solution of $[\mathrm{PdCl}(\pi \text {-allyl })]_{2}$ to the insoluble polymer catalyst and evaporation of the

Table 2 Palladium-catalyzed asymmetric hydrosilylation of styrene in the presence of reused PQXphos. ${ }^{\text {a }}$

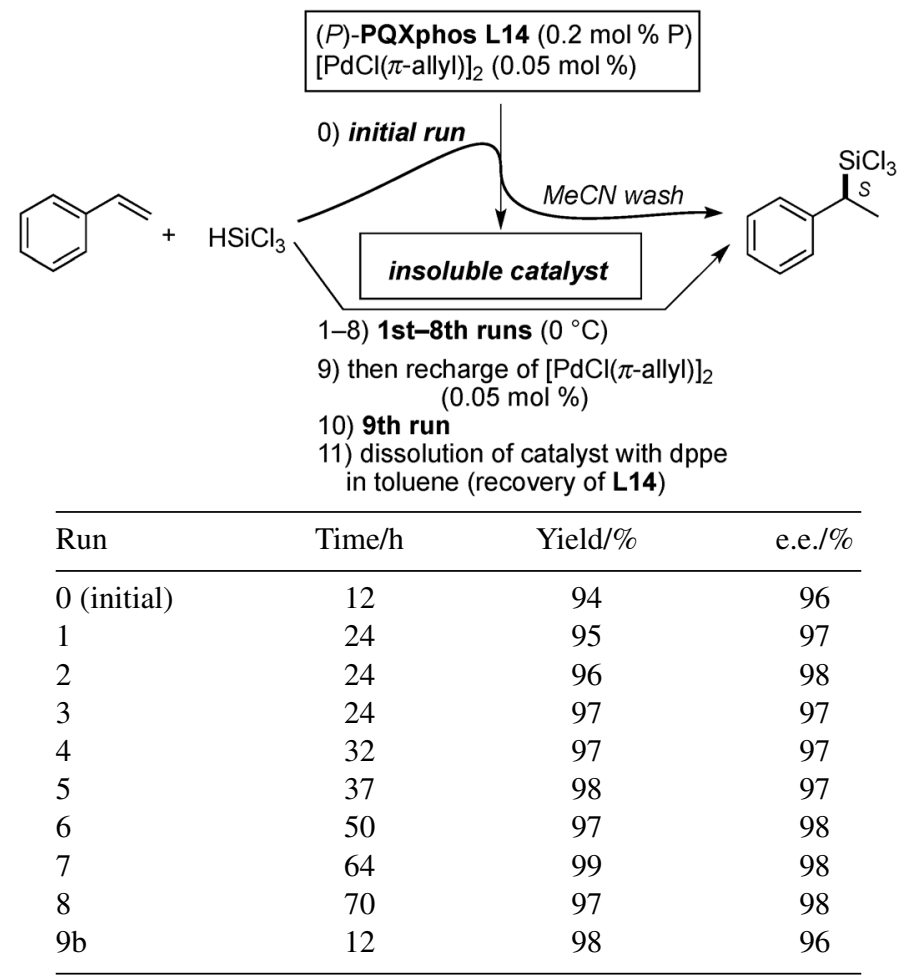

${ }^{\mathrm{a}} \mathrm{See}$ footnote a in Table 1 for the reaction conditions. Product was isolated by washing the reaction mixture with acetonitrile three times followed by bulb-to-bulb distillation.

${ }^{\mathrm{b}}$ After recharge of the palladium complex. 
solvent. Active and selective catalyst was regenerated to give the hydrosilylation product with the same yield and e.e. as those obtained in the first run (run 9, Table 2). Moreover, addition of 1,2-diphenylphosphinoethane (DPPE) to the solution of the polymer complex allows dissolution of the polymer, leading to the recovery of polymer ligand and palladium complex separately. We are now looking for a solvent that does not allow leaching but is suitable for product extraction.

In a recently published paper, we reported the solvent-dependent switch of helical chirality in the 40mer PQX bearing $(R)$-1-methylpropyloxymethyl side chains [10]. We checked the possibility of the solvent-dependent helix inversion with high-molecular-weight PQXphos L14, observing clean inversion of the helical sense. The $(R)$-1-methylpropyloxymethyl side chains induced right-handed $(P)$-helical structures in chloroform and toluene, but induced left-handed $(M)$-helical structures in 1,1,2-trichloroethane (1,1,2-TCE). PQXphos L14 thus far employed takes the ( $P$ )-helical sense because they are isolated from their toluene solution, and its helical sense can be inverted to $(M)$-helix by heating its $1,1,2$-TCE/toluene (2/1) solution at $60{ }^{\circ} \mathrm{C}$ for $6 \mathrm{~h}$ (Scheme 1$)$. The inverted PQXphos $(M)-\mathbf{L} 14$ was used in hydrosilylation of styrene in $1,1,2-\mathrm{TCE} /$ toluene at $0{ }^{\circ} \mathrm{C}$. We found that the $(R)$-hydrosilylation product was formed in high yield with high enantioselectivity (93\%). This example may show an advantage of using a polymer scaffold as a chiral catalyst in asymmetric catalysis.

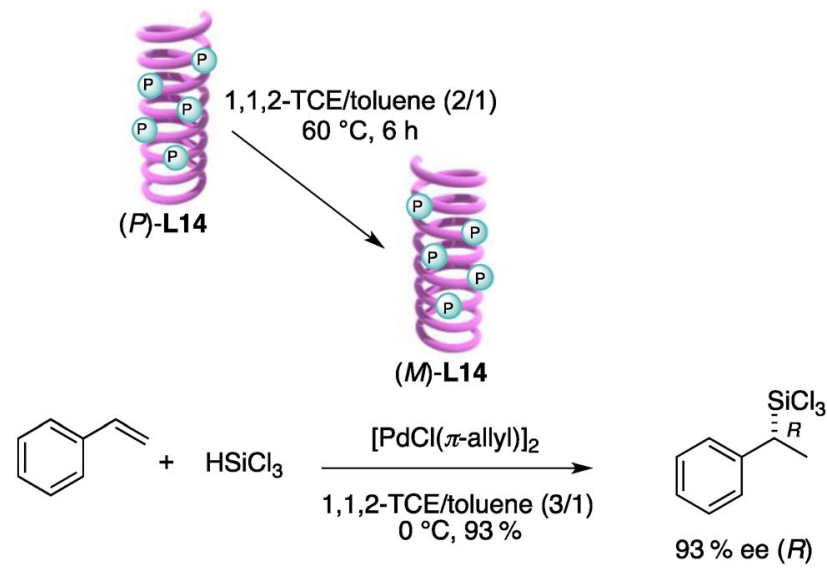

Scheme 1

\section{ASYMMETRIC SYNTHESIS OF AXIALLY CHIRAL BIARYLS VIA ASYMMETRIC SUZUKI-MIYAURA COUPLING USING PQXphos}

We wished to extend the PQXphos ligand as a highly efficient chiral ligand to other asymmetric catalyses. We were interested in pursuing asymmetric formation of axially chiral $\mathrm{C}-\mathrm{C}$ bonds, simply because the helical conformation is built up with a number of induced axial chiralities between quinoxaline rings. Suzuki-Miyaura coupling could be a good candidate to make it, although not many precedents with high enantioselectivity exist [16]. Following the initial report by Buchwald and Jin in 2000 using KenPhos as a chiral ligand [17], highly enantioselective systems have been established by Cammidge (2000), Bermejo (2008), and Uozumi (2009) for highly enantioselective Suzuki-Miyaura biaryl synthesis [18-20]. Our particular focus was on the Buchwald system, in which synthetically useful biarylphosphonates are obtained in highly enantioenriched form.

Cross-coupling of 1-bromonaphthylphosphonate 1a with $o$-tolylboronate 2a in the presence of 20mer-based PQXphos L9, which bears chiral side chains, gave cross-coupling product $(S)$-3a in $71 \%$ e.e. at $80{ }^{\circ} \mathrm{C}$ in $\mathrm{THF} / \mathrm{H}_{2} \mathrm{O}$ (entry 1 , Table 3 ). The enantioselectivity was improved to $78 \%$ e.e. by lowering the reaction temperature to $40{ }^{\circ} \mathrm{C}$ (entries 2 and 3). We then tested 20mer-based PQXphos 
L10-L12, which carry various diarylphosphino groups, under the same reaction conditions (entries 4-6). Examination revealed that the enantioselectivities largely depended on the aryl groups on the phosphorus group. L10 and L11, which have 3,5-xylyl and $p$-tolyl groups on the phosphorus atoms, respectively, exhibited remarkably higher enantioselectivities than did diphenylphosphino derivative $\mathbf{L 9}$ (entries 4 and 5). In contrast, $\mathbf{L 1 2}$ bearing a 3,5-bis(trifluoromethyl)phenyl group showed significantly lower enantioselectivities than the other ligands (entry 6). Use of the corresponding high-molecularweight PQXphos was found to afford higher enantioselectivities. For instance, diphenylphosphino-substituted high-molecular-weight PQXphos L14 resulted in $83 \%$ e.e., which is significantly higher than the $78 \%$ e.e. with L9 (entries 3 and 7). Use of 3,5-xylyl- (L15) and 2-naphthyl-substituted (L16) highmolecular-weight PQXphos afforded enantioselectivities higher than $90 \%$ e.e. (entries 8 and 9). The result was found to be superior to the original system using KenPhos, which gave $86 \%$ e.e. Attempted use of dicyclohexylphosphino-substituted PQXphos $\mathbf{L 1 7}$ resulted in significantly lower enantioselectivity compared with KenPhos bearing the particular dialkylphosphino group.

Table 3 Palladium-catalyzed Suzuki-Miyaura coupling of $\mathbf{1}$ with $\mathbf{2}$ in the presence of PQXphos as chiral ligands. ${ }^{\mathrm{a}}$

\begin{tabular}{|c|c|c|c|c|c|}
\hline & 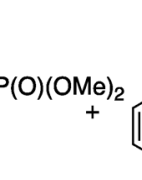 & $\begin{array}{l}\mathrm{H})_{2} \\
\mathrm{Me}\end{array}$ & $\begin{array}{l}\text { PQXphos } \\
1 \% \text { Pd catalyst } \\
\text { \%/Pd = 2/1) } \\
\mathrm{K}_{3} \mathrm{PO}_{4} \\
\mathrm{H}_{2} \mathrm{O}(10 / 1)\end{array}$ & | & \\
\hline Entry & PQXphos & Temp $/{ }^{\circ} \mathrm{C}$ & Time/h & Yield/\%b & e.e. $/ \%^{\mathrm{c}}$ \\
\hline 1 & L9 & 80 & 22 & 57 & 71 \\
\hline 2 & L9 & 60 & 24 & 70 & 74 \\
\hline 3 & L9 & 40 & 180 & 62 & 78 \\
\hline 4 & L10 & 40 & 96 & 81 & 86 \\
\hline 5 & L11 & 40 & 96 & 74 & 84 \\
\hline 6 & L12 & 40 & 108 & 41 & 35 \\
\hline 7 & L14 & 40 & 48 & 78 & 83 \\
\hline 8 & L15 & 40 & 48 & 69 & 92 \\
\hline 9 & L16 & 40 & 48 & 80 & 94 \\
\hline 10 & L17 & 40 & 48 & 72 & 40 \\
\hline
\end{tabular}

aReaction conditions for entries 1-6: 1a, $2 \mathbf{a}$ (1.5 equiv), $\mathrm{Pd}_{2}(\mathrm{dba})_{3}(1 \mathrm{~mol} \%)$, the polymer ligand ( $4.8 \mathrm{~mol} \% \mathrm{P}$ ), and $\mathrm{K}_{3} \mathrm{PO}_{4}$ (3 equiv) were heated in $\mathrm{THF}$ and $\mathrm{H}_{2} \mathrm{O}$; for entries 7-10: 1a, 2a (1.5 equiv), $[\mathrm{PdCl}(\pi \text {-allyl })]_{2}(1.0 \mathrm{~mol} \%)$, ligand $(4.0 \mathrm{~mol} \% \mathrm{P})$, and $\mathrm{K}_{3} \mathrm{PO}_{4}$ (2 equiv) were heated in THF and $\mathrm{H}_{2} \mathrm{O}$.

bIsolated yield.

cDetermined by HPLC (chiral stationary phase).

Some other coupling reactions were carried out using high-molecular-weight PQXphos L14-L16 (Scheme 2). Coupling of 1 with 1-binaphthylboronic ester afforded 1,1'-binaphthyl-2-phosphonate $\mathbf{3 b}$ with high enantioselectivity. In this reaction, $\mathbf{L 1 4}$ afforded the highest selectivity of $94 \%$ e.e., although the other two ligands L15 and L16 also gave similarly high enantioselectivities of 92 and $90 \%$ e.e., respectively. In the cross-couplings of $o$-methyl-substituted arylboronic acids, $\mathbf{L 1 5}$ or L16, were always superior to L14. In the cross-coupling of 2,3-xylylboronic acid, $98 \%$ e.e. has been obtained with L16, while $\mathbf{L 1 4}$ afforded $92 \%$ e.e. 


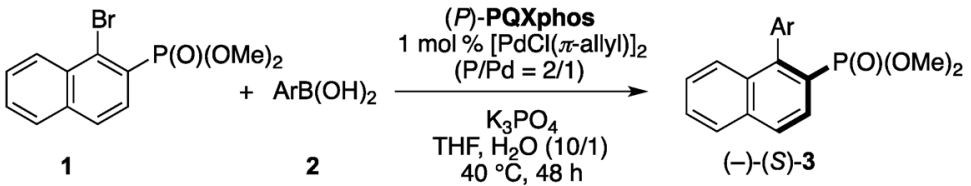

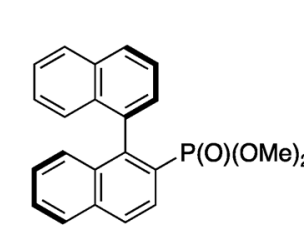

$(-)-(S)-3 b$

$94 \%$ ee, 42 \% (L14)<smiles>COc1ccc(-c2c(P(C)OC)ccc3ccccc23)c(C)c1</smiles>

$(-)-(S)-3 c$ $95 \%$ ee, $84 \%$ (L15)<smiles>COc1ccc2ccccc2c1-c1cccc(C)c1OC</smiles>

$(-)-(S)-3 \mathbf{d}$ $98 \%$ ee , $78 \%$ (L16)<smiles>COc1ccc2ccccc2c1-c1cc(C)ccc1OC(C)C</smiles>

$(-)-(S)-3 e$

$94 \%$ ee, $93 \%$ (L16)<smiles>COc1ccc2ccccc2c1-c1ccc(Cl)cc1[N+](=O)[O-]</smiles>

$(-)-(S)-3 \mathbf{f}$

$94 \%$ ee, 60 \% (L16)

Scheme 2

We finally examined the use of $(M)$-L16, whose helical chirality was switched by heating $\mathbf{L 1 6}$ in 1,1,2-TCE/THF at $60{ }^{\circ} \mathrm{C}$ for $24 \mathrm{~h}$ (Scheme 3). Cross-coupling of 1 with 2,3-xylylboronic acid in a $1,1,2$-TCE/THF mixture at $40{ }^{\circ} \mathrm{C}$ afforded the $(R)$-coupling product with $90 \%$ e.e. Although the enantioselectivity was a little lower than the native $(P)$-L16, the helically inverted $(M)$-L16 successfully gave comparable enantioselectivity for the production of the enantiomeric product.

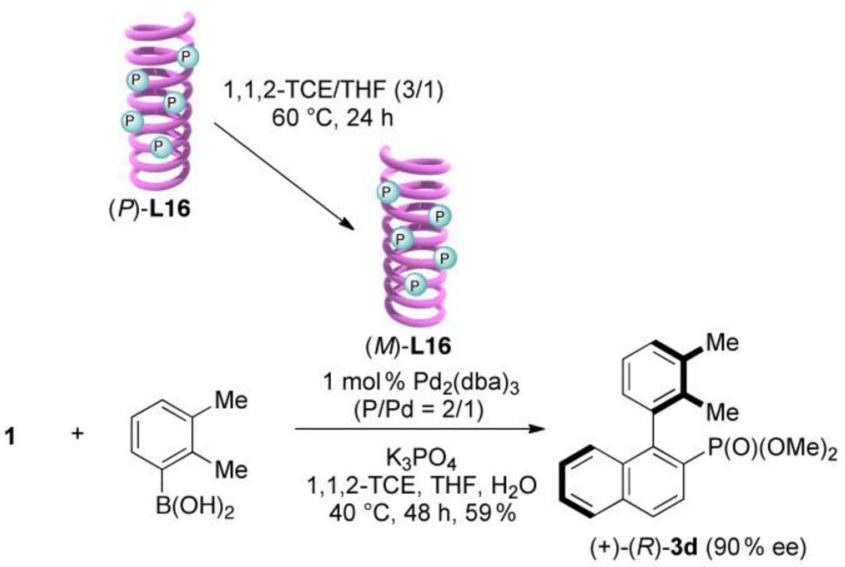

Scheme 3 


\section{SUMMARY AND CONCLUSION}

In summary, we have shown that helically chiral PQXphos serves as a highly enantioselective ligand in the asymmetric hydrosilylation of styrene and asymmetric Suzuki-Miyaura coupling reactions to form axially chiral biarylphosphinic esters. In addition to the easy reuse of the chiral catalyst by virtue of the formation of a polymer complex, reversible conformational change of the polymer backbone could be applied to switch the enantioinduction in asymmetric catalysis. The organic groups on the phosphorus atom in the side chains of PQXphos have a significant effect on the enantioselectivities of the reactions. Further optimization of the ligand structure, attempts at expanding the substrate scope, and utilization of the polymer-based chiral ligands to other catalytic reactions are currently being undertaken in this laboratory.

\section{ACKNOWLEDGMENTS}

Financial support for this project was provided by the Japan Science and Technology Corporation (CREST, "Development of High-performance Nanostructures for Process Integration" Area) and in part by a Grant-in-Aid for Scientific Research from Ministry of Education, Culture, Sports, Science, and Technology, Japan.

\section{REFERENCES}

1. (a) M. R. Buchmeiser (Ed.). Polymeric Materials in Organic Synthesis and Catalysis, John Wiley, Weinheim (2003); (b) Z. Wang, G. Chen, K. Ding. Chem. Rev. 109, 322 (2009); (c) S. Ikegami, H. Hashimoto. Chem. Rev. 109, 583 (2009).

2. Reviews: (a) E. A. C. Davie, S. M. Mennen, Y. Xu, S. J. Miller. Chem. Rev. 107, 5759 (2007); (b) F. Rosati, G. Roelfes. ChemCatChem 2, 916 (2010).

3. (a) G. Roelfes, B. L. Feringa. Angew. Chem., Int. Ed. 44, 3230 (2005); (b) A. J. Boersma, B. L. Feringa, G. Roelfes. Org. Lett. 9, 3647 (2007); (c) D. Coquiére, B. L. Feringa, G. Roelfes. Angew. Chem., Int. Ed. 46, 9308 (2007); (d) A. J. Boersma, B. L. Feringa, G. Roelfes. Angew. Chem., Int. Ed. 48, 3346 (2009); review: (e) A. J. Boersma, R. P. Megens, B. L. Feringa, G. Roelfes. Chem. Soc. Rev. 39, 2083 (2010).

4. A. F. Trindade, P. M. P. Gois, C. A. M. Afonso. Chem. Rev. 109, 418 (2009).

5. (a) M. Reggelin, M. Schults, M. Holbach. Angew. Chem., Int. Ed. 41, 1614 (2002); (b) M. Reggelin, S. Doerr, M. Klussmann, M. Schults, M. Holbach. Proc. Natl. Acad. Sci. 101, 5461 (2004).

6. (a) Y. Okamoto, K. Suzuki, K. Ohta, K. Hatada, H. Yuki. J. Am. Chem. Soc. 101, 4763 (1979); (b) T. Nakano, Y. Okamoto. Chem. Rev. 101, 4013 (2001); (c) J. J. L. Cornelissen, A. E. Rowan, R. J. M. Nolte, N. A. J. M. Sommerdijk. Chem. Rev. 101, 4039 (2001); (d) E. Yashima, K. Maeda, H. Iida, Y. Furusho, K. Nagai. Chem. Rev. 109, 6102 (2009).

7. Y. Ito, E. Ihara, M. Murakami, M. Shiro. J. Am. Chem. Soc. 112, 6446 (1990).

8. Y. Ito, E. Ihara, M. Murakami. Angew. Chem., Int. Ed. Engl. 31, 1509 (1992).

9. (a) M. Suginome, S. Collet, Y. Ito. Org. Lett. 4, 351 (2002); for related studies, see: (b) Y. Ito, T. Ohara, R. Shima, M. Suginome. J. Am. Chem. Soc. 118, 9188 (1996); (c) Y. Ito, T. Miyake, S. Hatano, R. Shima, T. Ohara, M. Suginome. J. Am. Chem. Soc. 120, 11880 (1998); (d) Y. Ito, T. Miyake, T. Ohara, M. Suginome. Macromolecules 31, 1697 (1998); (e) Y. Ito, T. Miyake, M. Suginome. Macromolecules 33, 4034 (2000).

10. T. Yamada, Y. Nagata, M. Suginome. Chem. Commun. 46, 4914 (2010).

11. T. Yamamoto, M. Suginome. Angew. Chem., Int. Ed. 48, 539 (2009).

12. T. Yamamoto, T. Yamada, Y. Nagata, M. Suginome. J. Am. Chem. Soc. 132, 7899 (2010).

13. T. Yamamoto, Y. Akai, Y. Nagata, M. Suginome. Angew. Chem., Int. Ed. 50, 8844 (2011). 
14. (a) Y. Ito, E. Ihara, M. Murakami. Polym. J. 24, 297 (1992); (b) T. Yamada, H. Noguchi, Y. Nagata, M. Suginome. J. Polym. Sci., Part A: Polym. Chem. 48, 898 (2010); (c) T. Yamada, M. Suginome. Macromolecules 43, 3999 (2010).

15. (a) Y. Uozumi, T. Hayashi. J. Am. Chem. Soc. 113, 9887 (1991); (b) T. Hayashi, S. Hirate, K. Kitayama, H. Tsuji, A. Torii, Y. Uozumi. J. Org. Chem. 66, 1441 (2001); (c) T. Hayashi. Acc. Chem. Res. 33, 354 (2000).

16. (a) N. Miyaura. Top. Curr. Chem. 219, 11 (2002); (b) A. Suzuki, H. C. Brown. Organic Synthesis via Boranes, Vol. 3, Aldrich, Milwaukee (2003); (c) N. Miyaura, A. Suzuki. Chem. Rev. 95, 2457 (1995).

17. (a) J. Yin, S. L. Buchwald. J. Am. Chem. Soc. 122, 12051 (2000); (b) X. Shen, G. O. Jones, D. A. Watson, B. Bhayana, S. L. Buchwald. J. Am. Chem. Soc. 132, 11278 (2010).

18. (a) A. N. Cammidge, K. V. L. Crépy. Chem. Commun. 1723 (2000); see also: (b) M. Genov, A. Almorín, P. Espinet. Chem.-Eur. J. 12, 9346 (2006).

19. A. Bermejo, A. Ros, R. Fernández, J. M. Lassaletta. J. Am. Chem. Soc. 130, 15798 (2008).

20. Y. Uozumi, Y. Matsuura, T. Arakawa, Y. M. A. Yamada. Angew. Chem., Int. Ed. 48, 2708 (2009). 